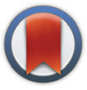

CrossMark \& click for updates

Cite this: Polym. Chem., 2016, 7, 1239 Accepted 11th January 2016

DOI: $10.1039 / c 5 p y 01872 b$

www.rsc.org/polymers
Received 24th November 2015,

\section{Synthesis of stereodiblock polyisoprene consisting of cis-1,4 and trans-1,4 sequences by using a neodymium catalyst: change of the stereospecificity triggered by an aluminum compound $\dagger$}

\author{
Ryo Tanaka, * Kaede Yuuya, Hiroki Sato, Peter Eberhardt, Yuushou Nakayama and \\ Takeshi Shiono*
}

The first example of the synthesis of stereodiblock polyisoprene which consists of cis-1,4 and trans $-1,4$ sequences was achieved by using a neodymium catalyst. The stereospecificity was controlled by the ratio of $\mathrm{Bu}_{2} \mathrm{Mg}$ and modified methylaluminoxane (MMAO), and by sequential addition of $\mathrm{Bu}_{2} \mathrm{Mg}$ and MMAO, a geometrically well-defined stereodiblock polymer was obtained.

A stereoblock polymer, which contains multiple different stereosequences in one polymer chain, changes its physical properties from the original stereoregular polymer. One strategy to synthesize such a polymer is exchanging a propagating chain between two different metal species by equilibrium. Sita applied activated cationic zirconium for the isospecific propylene polymerization and unactivated neutral zirconium species for the racemization of stereocenters which are in equilibrium, giving an isotactic-atactic stereomultiblock polypropylene. ${ }^{1}$ This stereomultiblock polypropylene shows elastomeric properties, whereas isotactic polypropylene shows crystallinity. More simply, mixing two different polymerization catalysts with a chain transfer reagent can also afford the isotacticcapped syndiotactic polystyrene ${ }^{2}$ and isotactic-syndiotactic stereomultiblock polypropylene. ${ }^{3}$ Sometimes a isostructural catalyst performs as an equilibrium of two kinds of catalysts with different symmetries by occasional flipping of the polymer chain or the rotation of the ligand during propylene polymerization, resulting in the formation of isotactic and atactic polypropylene blocks. ${ }^{4,5}$

Another way to synthesize stereoblock polymers is using a living polymerization system and changing the selectivity by external stimuli during polymerization (Scheme 1). In this synthetic strategy, the lengths of each block can be controlled precisely by the polymerization time. We have previously reported the synthesis of di- or triblock polypropylene which consists of

Graduate School of Engineering, Hiroshima University, 1-4-1 Kagamiyama, Higashihiroshima, Hiroshima, 739-8527 Japan. E-mail: rytanaka@hiroshima-u.ac.jp $\dagger$ Electronic supplementary information (ESI) available: NMR spectra and DSC traces of the obtained polymer. See DOI: 10.1039/c5py01872b

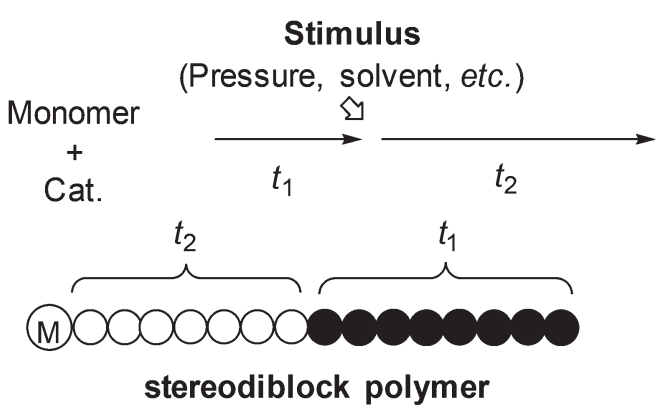

Scheme 1 Synthetic strategy of stereodiblock polymers by changing the stereospecificity of living polymerization with an external stimulus.

syndiotactic and atactic sequences by changing the reaction temperature, ${ }^{6}$ solvent $^{7}$ or monomer concentration. ${ }^{8}$ However, none of them have control over two different high stereoregularities. Namely, they just control stereospecific polymerization and non-stereospecific polymerization.

Additives are among the most fundamental tools to control the selectivity of the metal-catalyzed reaction. In the coordination polymerization of olefins, the stereospecificity strongly depends on the symmetry of the catalyst and therefore it is difficult to control with additives. However, in the polymerization of conjugated dienes, a small amount of additives sometimes dramatically change the stereospecificities. For example, a cis/trans- or 1,4/1,2-specificity of butadiene polymerization can be controlled by the ratio of phosphine and metal precursors such as $\mathrm{Ni}(\mathrm{tfa})_{2}{ }^{9}$ and $\mathrm{CoCl}_{2}{ }^{10,11}$ activated by methylaluminoxane (MAO). In addition, main group metal alkyls, which can coordinate to transition metal with $\sigma$-bond bridges, are also applied as additives. The cis/trans-1,4 specificity of the isoprene polymerization catalyzed by $\mathrm{Nd}\left(\mathrm{BH}_{4}\right)_{3}(\text { thf })_{3}{ }^{12-14}$ or $\mathrm{Y}(\operatorname{allyl})_{2} \mathrm{Cl}\left(\mathrm{MgCl}_{2}\right)_{2}(\mathrm{thf})_{4}{ }^{15}$ is varied with activators such as $\mathrm{Bu}_{2} \mathrm{Mg}, \mathrm{Ph}_{3} \mathrm{CB}\left(\mathrm{C}_{6} \mathrm{~F}_{5}\right)_{4},{ }^{\mathrm{i}} \mathrm{Bu}_{3} \mathrm{Al}$ and MAO. Switching 3,4- and cis-1,4 specificities by the addition of $\mathrm{Me}_{3} \mathrm{Al}$ to the yttrium amidinate catalyst is also reported. ${ }^{16}$ The application of these 
additive effects to living polymerization systems would open up the way to the synthesis of stereodiblock polymers. As the first example, we were motivated to investigate the synthesis of geometrically well-defined stereodiblock ${ }^{17}$ polyisoprene using a neodymium catalyst activated by $\mathrm{Bu}_{2} \mathrm{Mg}$, controlling cis-1,4 and trans-1,4 specificities in the living manner.

$\mathrm{Nd}\left(\mathrm{BH}_{4}\right)_{3}(\text { thf })_{3}$ activated by $\mathrm{Bu}_{2} \mathrm{Mg}$ can promote the trans1,4 specific isoprene polymerization in a living manner (Table 1, run 1). For the synthesis of stereodiblock polyisoprene, the trans-1,4 specificity should be shifted to cis-1,4 in a living manner. Therefore, we first investigated the effect of several aluminum additives on the stereospecificity of isoprene polymerization. The $1,4 / 3,4$ specificity was determined by ${ }^{1} \mathrm{H}$ NMR and the cis/trans specificity was determined by ${ }^{13} \mathrm{C} \mathrm{NMR} .{ }^{18}$

An excess amount of modified methylaluminoxane (MMAO), which was prepared by the partial hydrolysis of ${ }^{\mathrm{i}} \mathrm{Bu}_{3} \mathrm{Al}$ and $\mathrm{Me}_{3} \mathrm{Al}$ greatly increased the cis-1,4 specificity and activity so that the reaction proceeded at room temperature. The cis-1,4 ratio increased according to the $\mathrm{Al} / \mathrm{Mg}$ ratio, whereas the 3,4-selectivity remained unchanged (runs 1-5). The molecular weight distribution became narrower and the cis-1,4 specificity was improved by the addition of ${ }^{t} \mathrm{BuCl}$, although the polymerization rate was decreased (run 6). The addition of $\mathrm{Me}_{2} \mathrm{SiCl}_{2}$ to dried MMAO (dMMAO) also gave a narrow molecular weight polymer (run 8). The use of ${ }^{\mathrm{i}} \mathrm{Bu}_{3} \mathrm{Al}$ gave small molecular weight poly(cis-1,4-isoprene), which is because of the frequent chain transfer between neodymium and aluminium (run 8). Such a tendency was also observed when $\mathrm{Cp}^{*} \mathrm{La}\left(\mathrm{BH}_{4}\right)_{2}$ (thf $)_{2}$ was used as a catalyst precursor, although the change of selectivity from trans to cis did not take place. ${ }^{19}$ Using $\mathrm{MAO}$, which contains $30 \mathrm{~mol} \%$ of $\mathrm{Me}_{3} \mathrm{Al}$ (run 9), instead of MMAO decreased the activity probably because small $\mathrm{Me}_{3} \mathrm{Al}$ can suppress the polymerization by coordinating to the cationic neodymium active species. MMAO alone did not promote the polymerization, indicating that cationic neodymium-alkyl species was not generated only by MMAO (run 10).

The ${ }^{13} \mathrm{C}$ NMR spectrum of polyisoprene obtained by using the $\mathrm{Nd}-\mathrm{Mg} / \mathrm{Al}$ system (Table 1 , run 4, cis $:$ trans $=59: 37$ ) in the region of carbon at the 1-position (31-41 ppm) is shown in Fig. 1. Four peaks are observed corresponding to the tactic dyads, which are assigned to cis-trans (23\%), trans-trans (16\%), cis-cis (38\%), and trans-cis (23\%). The integral ratios of all the four peaks follow the statistical probability, showing that the cis-trans unit is randomly distributed in this polyisoprene.

In general, the cis/trans stereospecificity in the coordination polymerization of isoprene is determined as follows: when isoprene coordinates to the metal center in a $c i s-\eta^{4}$-manner, the following insertion gives anti- $\pi$-allyl species. Normally, the syn$\pi$-allyl configuration which gives the trans-1,4 sequence is more stable than the anti- $\pi$-allyl configuration which gives the

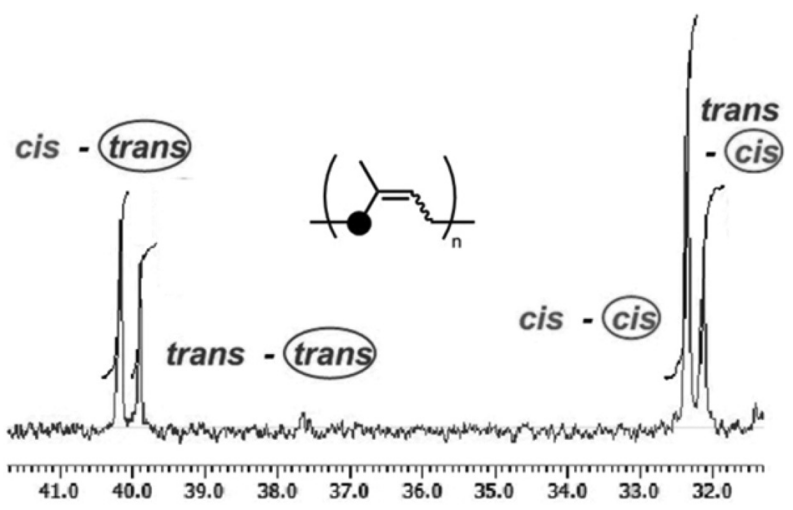

Fig. 1 A part of the ${ }^{13} \mathrm{C}$ NMR spectrum of polyisoprene synthesized by using the $\mathrm{Nd}-\mathrm{Mg} / \mathrm{Al}$ catalyst system $\left(125 \mathrm{MHz}\right.$, in $\mathrm{CDCl}_{3}$, Table 1, run 4).

Table 1 Effect of aluminum compounds on the polymerization of isoprene using the $\mathrm{Nd}\left(\mathrm{BH}_{4}\right)_{3}\left(\mathrm{thf}_{3}-\mathrm{Bu}_{2} \mathrm{Mg}_{\mathrm{s}}\right.$ stem ${ }^{\mathrm{a}}$

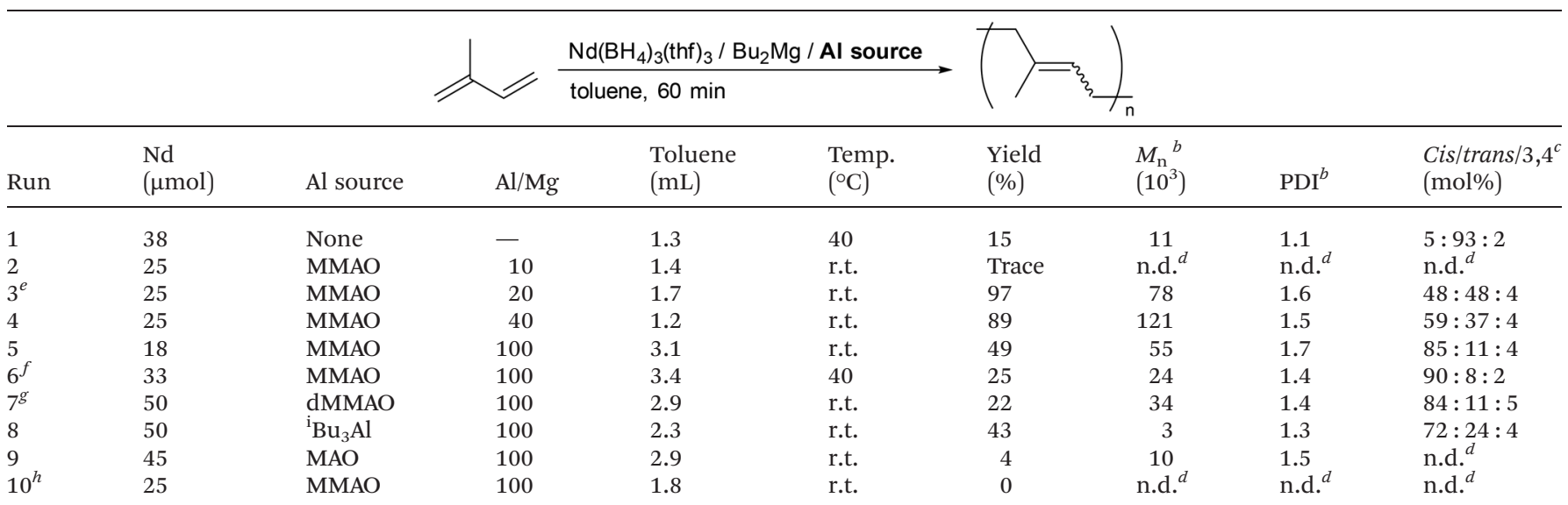

${ }^{a}$ Reaction conditions: [isoprene]/[Nd] $=625,\left[\mathrm{Bu}_{2} \mathrm{Mg}\right] /[\mathrm{Nd}]=1$, time $=60 \mathrm{~min}$, and solvent $=$ toluene. ${ }^{b}$ Determined by GPC calibrated with the polystyrene standard. ${ }^{c}$ Determined by ${ }^{1} \mathrm{H}$ and ${ }^{13} \mathrm{C}$ NMR. ${ }^{d}$ Not determined. ${ }^{e}$ The amount of $\mathrm{Bu}_{2} \mathrm{Mg}$ was 2 equiv. of Nd. ${ }^{f} 1$ equiv. of ${ }^{t} \mathrm{BuCl}$ was added and the time was 10 h. ${ }^{g} 0.25$ equiv. of $\mathrm{Me}_{2} \mathrm{SiCl}_{2}$ was added. ${ }^{h} \mathrm{Bu}_{2} \mathrm{Mg}$ was not added. 
cis-1,4 sequence because of the steric hindrance of the polymer chain. Therefore, the trans-1,4 sequence is obtained when the anti-syn configurational equilibrium is fast enough compared with the propagation. The cis-1,4 sequence is obtained when the propagation is faster than the anti-syn equilibrium, namely, as a kinetic product. When isoprene coordinates in a trans- $\eta^{4}$-manner, the $s y n$ - $\pi$-allyl intermediate, which gives the trans-1,4 sequence, would be obtained regardless of the rate of the anti-syn equilibrium. ${ }^{20}$

Alkylmagnesium is considered as an alkylating reagent and the NMR investigation implies that $\mathrm{Nd}-\mathrm{Mg}$ bimetallic species is formed in the previously reported $\mathrm{Nd}-\mathrm{Bu}_{2} \mathrm{Mg}$ system. ${ }^{12,21}$ Taube reported trans-1,4 specific polymerization of butadiene using $\left(\mathrm{C}_{3} \mathrm{H}_{5}\right)_{3} \mathrm{Nd}$ and the stereospecificity is because of the steric hindrance of the propagating chain forcing the butadiene monomer to bind in a trans $-\eta^{4}$ or $\eta^{2}$ manner. ${ }^{22}$ The trans-specificity of $\mathrm{Nd}\left(\mathrm{BH}_{4}\right)_{3}(\text { thf })_{3}-\mathrm{Bu}_{2} \mathrm{Mg}$ can also be derived by following this mechanism: the isoprene coordinates to the neutral neodymium species in a trans $-\eta^{4}$ or $\eta^{2}$ manner because of the steric hindrance of alkylmagnesium, and the following syn- $\pi$-allyl intermediate would give the trans-1,4 sequence.

On the other hand, a cationic neodymium catalyst from $\mathrm{Nd}\left(\mathrm{BH}_{4}\right)_{3}(\text { thf })_{3}{ }^{23}$ or neutral dialkyl neodymium $\left(\mathrm{C}_{3} \mathrm{H}_{5}\right)_{2} \mathrm{NdCl}^{24}$ can promote the cis-1,4 specific polymerization of conjugated dienes. Excess alkylaluminum can form a dimer with magnesium and a naked neodymium is generated, which can derive the enhancement of the propagation rate and allow isoprene to coordinate in a $c i s-\eta^{4}$ manner. As a result, a kinetic cis-1,4 product would be obtained. In our mixed cocatalyst system, a fast equilibrium between $\mathrm{Nd}-\mathrm{Mg}$ bimetallic species and $\mathrm{Mg}-\mathrm{Al}$ multimetallic species would propagate the cis/trans random sequences (Fig. 2). The relatively broad molecular weight distribution when MMAO is applied is probably because of the deactivation of the unstable naked cationic active species. The addition of chloride would prevent the deactivation by coordinating to the neodymium center. ${ }^{25,26}$
The synthesis of stereodiblock polymers by the sequential addition of $\mathrm{Bu}_{2} \mathrm{Mg}$ and $\mathrm{MMAO} /{ }^{t} \mathrm{BuCl}$ or $\mathrm{dMMAO} / \mathrm{Me}_{2} \mathrm{SiCl}_{2}$ was performed (Table 2 ). In both systems, a polymer with a narrow molecular weight distribution was obtained in high yield. The GPC trace of the obtained polymer shifted to higher molecular weight from the prepolymer obtained using the $\mathrm{Nd}-\mathrm{Bu}_{2} \mathrm{Mg}$ system with a narrow molecular weight distribution (Fig. 3). This result strongly suggested that the polymer was obtained in a living manner. The integral ratios of cis-cis and transtrans dyads from ${ }^{13} \mathrm{C}$ NMR were much higher than the others, indicating the formation of a stereodiblock polymer which consists of cis- and trans-polyisoprene sequences (Fig. 4).

The synthesized cis-trans stereodiblock polyisoprene in Table 2 , run 2 showed a melting point $\left(T_{\mathrm{m}}\right)$ at $33^{\circ} \mathrm{C}$, which was almost the same value with trans-1,4-polyisoprene obtained in Table 1 , run $1\left(37^{\circ} \mathrm{C}\right)$, although the melting

Table 2 Synthesis of stereodiblock polyisoprene using the $\mathrm{Nd}-\mathrm{Mg} / \mathrm{Al}$ system $^{a}$

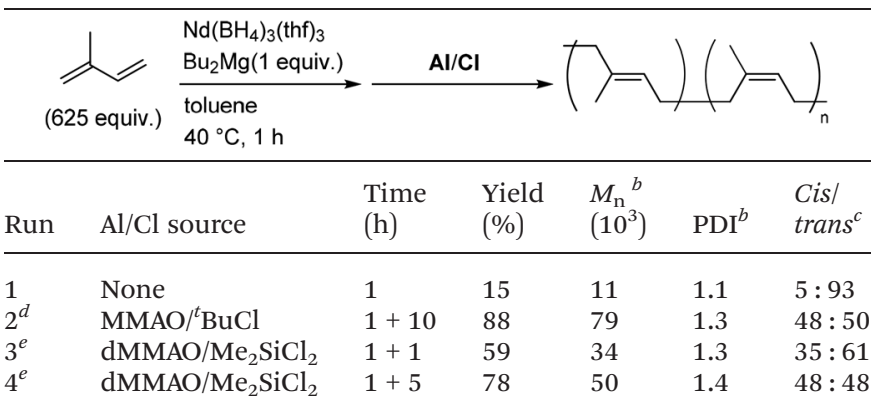

${ }^{a}$ Reaction conditions for the first block: [isoprene] $/[\mathrm{Nd}]=625$, $\left[\mathrm{Bu}_{2} \mathrm{Mg}\right] /[\mathrm{Nd}]=1$, temp. $=40{ }^{\circ} \mathrm{C}$, time $=1 \mathrm{~h}$, and solvent $=$ toluene. ${ }^{b}$ Determined by GPC calibrated with the polystyrene standard. ${ }^{c}$ Determined by ${ }^{1} \mathrm{H}$ and ${ }^{13} \mathrm{C}$ NMR. ${ }^{d} \mathrm{Nd}=37 \mathrm{~mol},[\mathrm{Al}] /[\mathrm{Nd}]=100$, $[\mathrm{Cl}] /[\mathrm{Nd}]=1$, temp. $=40{ }^{\circ} \mathrm{C} .{ }^{e} \mathrm{Nd}=50 \mathrm{~mol},[\mathrm{Al}] /[\mathrm{Nd}]=100,[\mathrm{Cl}] /[\mathrm{Nd}]=$ 0.25 , temp. $=$ r.t.

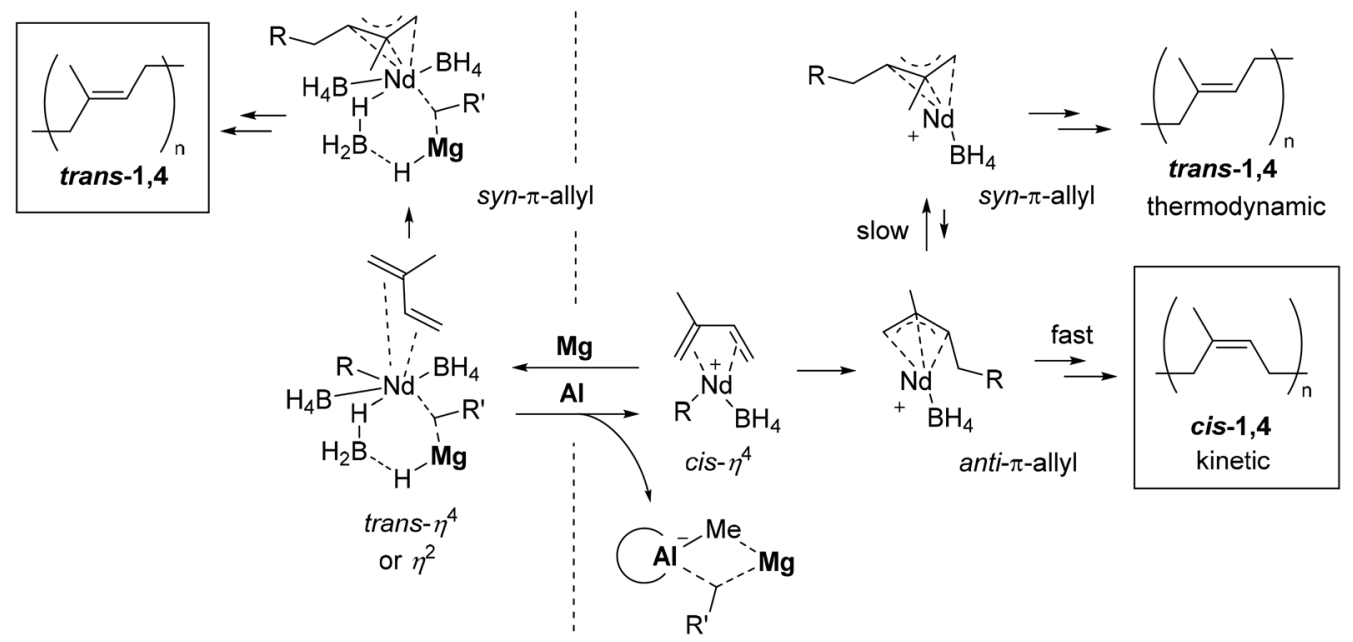

Fig. 2 Estimated active species and the mechanism of the change of stereospecificity in the polymerization of isoprene using the $\mathrm{Nd}-\mathrm{Mg} / \mathrm{Al}$ system. 


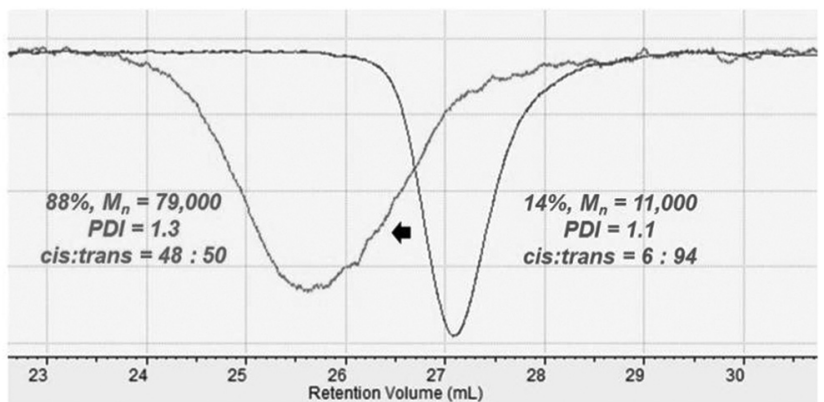

Fig. 3 GPC traces of trans-1,4-polyisoprene (right, Table 1, run 1) and trans-1,4-b-cis-1,4-polyisoprene (left, Table 2, run 2) measured at $150{ }^{\circ} \mathrm{C}$ in 1,2,4-trichlorobenzene.

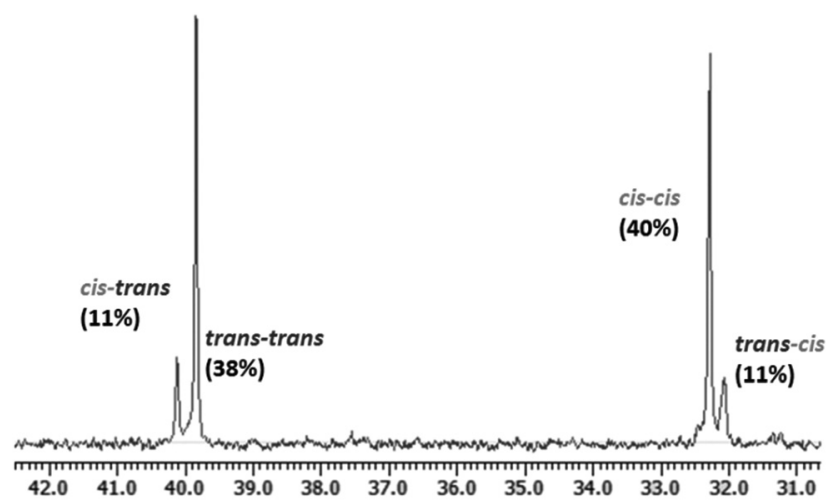

Fig. 4 A part of the ${ }^{13} \mathrm{C}$ NMR spectrum of trans-1,4-b-cis-1,4-polyisoprene obtained in Table 2, run $2\left(125 \mathrm{MHz}\right.$, in $\left.\mathrm{CDCl}_{3}\right)$.

enthalpy $(\Delta H)$ was much smaller compared with trans-1,4-polyisoprene $\left(7 v s .62 \mathrm{~J} \mathrm{~g}^{-1}\right)$. The decrease of the melting enthalpy was probably because of the high miscibility of cis-1,4 and trans $-1,4$ blocks. ${ }^{27}$ The tensile modulus of the stereodiblock polymer was 1.7 MPa, which was the typical value of an elastomeric material. Therefore, the synthesized stereodiblock polymer had both the crystallinity and elastomeric properties.

\section{Conclusions}

In conclusion, we succeeded in controlling the cis/trans-1,4 selectivity of isoprene polymerization initiated by $\mathrm{Nd}$ $\left(\mathrm{BH}_{4}\right)_{3}(\text { thf })_{3}$ by the addition of $\mathrm{Bu}_{2} \mathrm{Mg}$ and MMAO. The cis-1,4 specificity reached $90 \%$ when the $\mathrm{Al} / \mathrm{Mg}$ ratio was 100 . The stereodiblock polymer which consists of cis-1,4 and trans-1,4 blocks was successfully synthesized by sequential addition of alkylmagnesium and MMAO in the presence of a monomer.

\section{Experimental section}

\section{General}

All manipulations were performed under nitrogen gas using standard Schlenk techniques. Modified methylaluminoxane
(MMAO, $6.5 \mathrm{wt} \% \mathrm{Al}, 2.17 \mathrm{M}$ in toluene) was donated by TosohFinechem Co. Dried MMAO was prepared according to the literature. ${ }^{28}$ Isoprene was distilled over $\mathrm{CaH}_{2}$ and stored with $4 \mathrm{~A}$ molecular sieves. $\mathrm{Bu}_{2} \mathrm{Mg}(1: 1$ mixture of $s$-butyl and $n$-butyl, 1.0 $\mathrm{M}$ in heptane) was purchased and used as received. $\mathrm{Nd}\left(\mathrm{BH}_{4}\right)_{3}(\text { thf })_{3}$ was synthesized according to the literature. ${ }^{29}$ Dry toluene was purchased from Kanto Chemical Co., Inc., and further dried over sodium metal. ${ }^{1} \mathrm{H}$ and ${ }^{13} \mathrm{C}$ NMR spectra of the polymer were measured by using a Varian $500 \mathrm{MHz}$ spectrometer using $\mathrm{CDCl}_{3}$ as a solvent. The obtained spectra were calibrated by the peaks originating from the solvent $\left({ }^{1} \mathrm{H}\right.$ : $\left.7.26 \mathrm{ppm},{ }^{13} \mathrm{C}: 77.16 \mathrm{ppm}\right)$. The number-average molecular weight $\left(M_{\mathrm{n}}\right)$ of the polymer was determined by using a Viscotec 350 HT-GPC chromatograph at $150{ }^{\circ} \mathrm{C}$ using 1,2 ,4-trichlorobenzene as an eluent calibrated with a RI/Viscometer/MALS triple detector, or Tosoh HLC-8320 at $40{ }^{\circ} \mathrm{C}$ using THF as an eluent calibrated with the PS standard. The polymer concentration of the injecting solution was $1 \mathrm{mg} \mathrm{mL}^{-1}$ and the injection volume was $0.2 \mathrm{~mL}$. DSC analyses of the polymer were performed by using a SII EXSTAR6000 system. The tensile modulus of the polymer was measured by using an Olientec RTC-1210A instrument following ISO $527-3 / 1 \mathrm{~B}$ at $25{ }^{\circ} \mathrm{C}$ with a drawing rate of $50 \mathrm{~mm} \mathrm{~min}^{-1}$.

\section{Isoprene polymerization was carried out using the} $\mathrm{Nd}\left(\mathrm{BH}_{4}\right)_{3}(\text { thf })_{3}-\mathrm{Bu}_{2} \mathrm{Mg} / \mathrm{MMAO}$ system (Table 1, run 5)

To a $20 \mathrm{~mL}$ Schlenk flask, $\mathrm{Nd}\left(\mathrm{BH}_{4}\right)_{3}(\mathrm{thf})_{3}(18 \mathrm{mg}, 44 \mu \mathrm{mol})$ and $\mathrm{Bu}_{2} \mathrm{Mg}$ in toluene ( $44 \mu \mathrm{mol}, 40 \mathrm{mM}, 1.1 \mathrm{~mL}$ ), and MMAO $(2.0 \mathrm{~mL}, 4.4 \mathrm{mmol})$ were charged and stirred at room temperature for 3 minutes. To the yellow solution, isoprene $(2.8 \mathrm{~mL}$, $28 \mathrm{mmol}$ ) was added. The reaction mixture was stirred at room temperature for 1 hour. The resulting solution was poured into acidic methanol containing $1 \mathrm{wt} \%$ of BHT and the precipitated solid was recovered. The polymer was dried under vacuum overnight until constant weight. $909 \mathrm{mg}$ (49\%) of a colorless viscous polymer was obtained.

\section{Synthesis of stereodiblock polyisoprene using the $\mathrm{Nd}\left(\mathrm{BH}_{4}\right)_{3}\left(\mathrm{thf}_{3}\right)_{3}-\mathrm{Bu}_{2} \mathrm{Mg} / \mathrm{MMAO} /{ }^{t} \mathrm{BuCl}$ system (Table 2, run 2)}

To a $20 \mathrm{~mL}$ Schlenk flask, $\mathrm{Nd}\left(\mathrm{BH}_{4}\right)_{3}(\text { thf })_{3}(15 \mathrm{mg}, 37 \mu \mathrm{mol})$ and $\mathrm{Bu}_{2} \mathrm{Mg}$ in toluene $(37 \mu \mathrm{mol}, 40 \mathrm{mM}, 0.93 \mathrm{~mL}$ ) were charged and stirred at room temperature for 3 minutes. To the yellow solution, isoprene $(2.34 \mathrm{~mL}, 23.4 \mathrm{mmol})$ was added. The reaction mixture was warmed to $40{ }^{\circ} \mathrm{C}$ and stirred for 1 hour. To the mixture was added the mixture of toluene solution of MMAO $(2.3 \mathrm{~mL}, 4.9 \mathrm{mmol})$ and ${ }^{t} \mathrm{BuCl}(4.0 \mu \mathrm{L}, 37 \mu \mathrm{mol})$ and further stirred for 10 hours. The resulting solution was poured into acidic methanol containing $1 \mathrm{wt} \%$ of BHT and the precipitated solid was recovered. The polymer was dried under vacuum overnight until constant weight. $1.40 \mathrm{~g}(88 \%)$ of a colorless polymer was obtained.

We are grateful to Tosoh Finechem Co. for generous donation of chemicals. We also gratefully acknowledge the Natural Science Center for Basic Research and Development (N-BARD), Hiroshima University for the high temperature NMR measurement. 


\section{Notes and references}

1 M. B. Harney, Y. Zhang and L. R. Sita, Angew. Chem., Int. Ed., 2006, 45, 2400-2404.

2 R. Po and S. Spera, Polym. J., 2010, 42, 416-418.

3 C. Descour, T. Macko, D. Cavallo, M. Parkinson, G. Hubner, A. Spoelstra, M. Villani and R. Duchateau, J. Polym. Sci., Part A: Polym. Chem., 2014, 52, 1422-1434.

4 D. T. Mallin, M. D. Rausch, Y.-G. Lin, S. Dong and J. C. W. Chien, J. Am. Chem. Soc., 1990, 112, 2030-2031.

5 G. W. Coates and R. M. Waymouth, Science, 1995, 267, 217219.

6 Z. Cai, Y. Nakayma and T. Shiono, Macromolecules, 2008, 41, 6596-6598.

7 Z. Cai, Y. Nakayma and T. Shiono, Kinet. Catal., 2006, 47, 274-277.

8 Z. Cai, Y. Nakayma and T. Shiono, Macromol. Res., 2010, 18, 737-741.

9 P. Hadjiandrreou, M. Julemont and P. Teyssie, Macromolecules, 1984, 17, 2455-2456.

10 D. C. D. Nath, T. Shiono and T. Ikeda, Macromol. Chem. Phys., 2003, 204, 2017-2022.

11 Z. Cai, M. Shinzawa, Y. Nakayama and T. Shiono, Macromolecules, 2009, 42, 7642-7643.

12 F. Bonnet, M. Visseaux, A. Pereira and D. Barbier-Baudry, Macromolecules, 2005, 38, 3162-3169.

13 M. Terrier, M. Visseaux, T. Chenal and A. Mortreux, J. Polym. Sci., Part A: Polym. Chem., 2007, 45, 2400-2409.

14 F. Bonnet, C. E. Jones, S. Semlali, M. Bria, P. Roussel, M. Visseaux and P. L. Arnold, Dalton Trans., 2013, 42, 790801.

15 N. Ajellal, L. Furlan, C. M. Thomas, O. L. Casagrande and J.-F. Carpentier, Macromol. Rapid Commun., 2006, 27, 338343.

16 L. Zhang, M. Nishiura, M. Yuki, Y. Luo and Z. Hou, Angew. Chem., Int. Ed., 2008, 47, 2642-2645.
17 Currently the use of term 'geometrical isomer' was strongly discouraged and the cis-trans isomer was categorized as a stereoisomer. Thus, these kinds of block polymers should be called as 'stereoblock polymers', although there is no stereogenic center in the polymer. See: (a) G. P. Moss, Pure Appl. Chem., 1996, 68, 2193-2222; (b) A. D. Jenkins, Pure Appl. Chem., 1981, 53, 733-752.

18 M. W. Duch and D. M. Grant, Macromolecules, 1970, 3, 165174.

19 A. Valente, P. Zinck, M. J. Vitorino, A. Mortreux and M. Visseaux, J. Polym. Sci., Part A: Polym. Chem., 2010, 48, 4640-4647.

20 R. Taube, H. Windisch and S. Maiwald, Macromol. Symp., 1995, 89, 393-409.

21 F. Bonnet, H. E. Dye, Y. El Kinani, C. Dietz, P. Roussel, M. Bria, M. Visseaux, P. Zinck and P. Mountford, Dalton Trans., 2015, 44, 12312-12325.

22 S. Maiwald, H. Weissenborn, C. Sommer and R. Taube, J. Organomet. Chem., 2001, 640, 1-9.

23 M. Visseaux, M. Mainil, M. Terrier, A. Mortreux, P. Roussel, T. Mathivet and M. Destarac, Dalton Trans., 2008, 45584561.

24 S. Maiwald, C. Sommer, G. Müller and R. Taube, Macromol. Chem. Phys., 2002, 203, 1029-1039.

25 G. Kwag, H. Lee and S. Kim, Macromolecules, 2001, 34, 5367-5369.

26 H. Guo, J. Bi, J. Wang, X. Zhang, S. Jiang and Z. Wu, Dalton Trans., 2015, 44, 9130-9139.

27 The properties of blended natural rubber and trans-1,4polyisoprene are well investigated. See: J.-S. Song, B.-C. Huang and D.-S. Yu, J. Appl. Polym. Sci., 2001, 82, 81-89.

28 H. Hagimoto, T. Shiono and T. Ikeda, Macromol. Rapid Commun., 2002, 23, 73-78.

29 S. M. Cendrowski-Guillaume, G. Le Gland, M. Nierlich and M. Ephritikhine, Organometallics, 2000, 19, 5654-5660. 